\title{
ON THE LIFE-HISTORY AND SYSTEMATIC POSITION OF THE ORGANISIIS CAUSING DRY TOP ROT OF SUGAR CANE
}

\author{
W. R. Ivimey Cook B. Sc., Ph. D. \\ Department of Botany, The University, Bristol, England.
}

In $1920 \mathrm{Matz}(5,6,7)$ described an organism which caused a disease of the sugar canes in Puerto Rico. He referred it to the genus Plasmodiophora, under the name P. vascularum Matz. In 1929 Dr. Melville T. Cook (1) made a further investigation and transferred the organism to the genus Ligniera on the grounds that since it caused no hypertrophy of the host tissue it should be relegated to that genus which was characterised by causing no hypertrophy. Certain peculiarities described by Dr. Cook made me doubtful if this organism was really a species of the genus Ligniera, and induced me to write to Dr. Cook and ask him if he would send me a specimen slide in order to compare it with the other species of the genus with which I was familiar. In reply Dr. Cook sent me all the slides he had and was kind enough to invite me to make what use I cared of the slides and to publish any results obtained in this journal. I very gladly accepted this kind offer as I at once saw that the organism differed very considerably from the other species of the genus Ligniera, and, in fact, from any of the species of the Plasmodiophoraceae which I had seen.

There are certain characteristies which, after a study of the Plasmodiophoraceae, one appreciates as always occurring in all the species. The most important is the appearance of the plasmodium. Even from the time when the nucleus of the original amoeba divides into two the most noticeable feature is the presence of the nuclei. Irrespective of what staining method is employed, the karyosomes of these nuclei stand out as deeply staining bodies, spherical in outline and surrounded at a little distance by a clearly defined nuclear membrane. The chromatin may not be so easily seen since it lies around the nuclear membrane, or it.may be that it is the presence of the chromatin which makes the nuclear membrane stain up when a dye is employed. Whichever is the case, these nuclei stand out elearly in the plasmodium, and, in slides stained with Iron Alum and Haematoxylin the plasmodia appear as a greyish mass spotted all over with small black bodies. Division of these nuclei is rarely seen, and 
stages in which there is any disappearance of the characteristic karyosome are so infrequent that in no slide would more than one per cent of the plasmodia show any other stage. Only when the plasmodia are mature does the karyosome disappear, but even there the nuclear membrane remains recognisable until chromatin again is seen in the nuclei. In Dr. Cook's slides, which were stained with various dyes, I was at once struck by the almost complete absence of any recognisable nuclei in the plasmodia. Dr. Cook noticed this himself and says in his paper (1) "Nuclei could not be seen in any of the preparations until the spores began to form and sometimes the nuclei were not visible even when spore formation was well advanced". This characteristic is unlike anything which I have seen in any of the species of the Plasmodiophoraceae which I have studied.

Being unable to reconcile the fungus with any of the other Plasmodiophoraceae, and finding it difficult to determine the systematic position of the organism present, I wrote again to Dr. Cook asking him for a supply of material fixed specially for me. Dr. Cook in reply sent me a quantity of material fixed in Bouin's Fluid which was made up as follows:

Formaldehyde (formalin)
Picric acid (satur. aq. sol.) 25 parts
Acetic acid_- 5 parts

The material was sectioned after embedding in wax and serial sections from $6-10 \mu$ in thickness were eut. These were then critically examined and compared with the slides previously sent me by Dr. Cook. At the same time I asked Dr. E. J. Butler F.R.S., of the Imperial Mycological Institute, Kew, to examine the slides and give me the benefit of his opinion on the parasite. In addition Mr. S. F. Ashby also examined and reported on the slides. Their observations agreed with the conclusion which I had also arrived at, namely that more than a single organism was present in the diseased canes, and I now propose to consider in detail the results of my study of the disease.

There are three distinct types of spherical or subspherical bodies present in the cells. The largest and most conspicuous are thin walled and in some slides frequently collapsed bodies $16-21 \mu$ in diameter (Pl. LIII fig. A). These occur almost exclusively in the larger vessels and are frequently developed in such numbers that they completely block the whole of the passage. The second type are smaller, measuring 14-16 $\mu$ in diameter. These have thicker walls which are double-contoured and contain a definite nucleus in which one or sometimes two nucleoli can be made out. They are not so frequent 
and are rarely found in the large vessels though they may oceur in the phloem or sometimes in the xylem parenchyma or even in the cortex. From their size and structure they correspond to the spores of Ligniera vascularum deseribed by Dr. Cook. The third spore type is somewhat irregular in shape, measuring from 10-12 $\mu$ in diameter, and when fully grown is seen to be made up of a number of small spherical bodies each containing a well-marked nuclear mass which stains up clearly.

In addition to these there appear two distinct types of amoeboid material from which the spore types are differentiated. The most recognisable type consists of large masses which despite repeated staining by various aniline dyes fail to shew any recognisable structure or nuclei (Pl. LIII fig. D). These correspond to Dr. Cook's plasmodia. They are restricted to the large vessels and also definitely form part of a life-cycle with the largest spore type since it has been found that the latter become differentiated from them. The second amoeboid structure consists of much smaller elements, which are restricted to the phloem and xylem parenchyma. These, shewing strueture and nuclei with a single well-defined nucleolus, have been repeatedly observed.

Finally there are present minute spherical bodies which stain very deeply. These frequently appear associated with the three other spore types and Mr. Ashby thinks that they are probably bacteria.

There seems no question that the organism which is chiefly responsible for the disease of Dry Top Rot of Sugar canes is this large amoeba and its associated large spore type, and I will first give an account of its life history. I propose to eall it Amoebosporus vascularum.

\section{The Life-History of Amoebosporus vascularum sp. nov.}

The amoeba, in the earliest stage found, consists of a uniform mass of protoplasm in which no differentiation of any kind is apparent. The protoplasm appears granular after fixation, whether fixed with Bouin's Fluid or with Flemming's solution. No nuclear structure could be seen in any of the preparations whatever dye had been used to stain it. These amoebae oceur in the spiral and annular tracheids and in the pitted vessels of the vascular bundles. As they increase in size the amoebae as a rule do not shew any further differentiation (Pl. LIV fig.), but occasionally the protoplasm develops vacuoles (Pl. LIV fig. 4). When mature the amoebae completely fill the vessel in which they have been growing and it appears that this acts as a stimulus for reproduction. The protoplasm 
becomes traversed by lines in which solid material is laid down. From this the walls of the large spherical cysts, already referred to, (Pl. LIV fig. 6), are formed. These cyst are, at first, spherical and contain a single nucleus. This is generally the first stage in which nuclei become clearly recognisable. It is possible in the early stages in cyst development, to stain them sufficiently to see something of their internal structure. The nucleus is central, surrounded by a granular cytoplasm in which highly refringent granules are present. These are not dissolved by dilute hydrochloric acid and appear to consist of silicates. After a time the nucleus divides into a number of parts and around each a small spherical mass of protoplasm is formed and a cell wall is secreted. These bodies are difficult to see since the wall of the cyst has by this time become hard and stains do not penetrate easily (Pl. LIII fig. B). There is no doubt, however, that spores are formed (Pl. LV fig. 8). Whether the cyst breaks at once or remains intact for some time could not be determined, but eventually the spores are shed and come to lie around the empty cysts, Pl. LV fig. 7. During the formation of the cysts all the protoplasm of the amoeba is not used up, (Pl. LIV fig. 5), and after the discharge of the spores much cytoplasm is found lying around them, so that they come to be embedded in the protoplasm of the original amoeba (Pl. LV fig. 7).

The germination of the spores is difficult to observe, and the author is not certain that the following stages form part of the same life-cycle. As far as he can see the spores germinate to produce a small spherical body containing a clearly marked nuclets (PI. LIV fig. 1 ), in which there is a vacuole associated with the nucleus. The protoplasm later becomes more vacuolated as the amoeba grows (Pl. LIV fig. 2). The sequence of stages shewing the development between that represented by Pl. LIV fig. 2 and Pl. LIV fig. 3 have not been found, but the author is quite certain that the large amoebae found are derived from these small bodies.

The life-cycle of this organism may be graphically represented by the following diagram: 


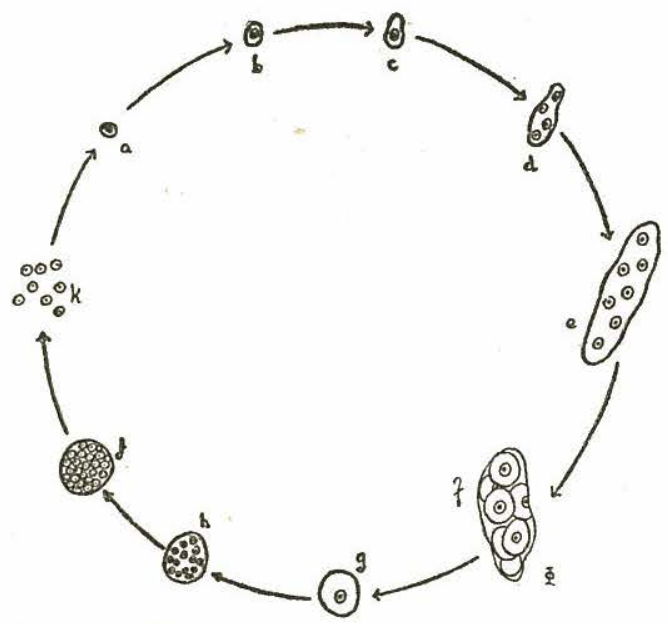

Diagram of Life-cycle of Amoebosporus vascularum. $a$. spore; $b$. germinated spore; c. young amoeba; d. multinucleate amoeba; e. mature amoeba; $f$. formation of cysts within amoeba; $g$. single cyst; $h$. multinucleate cyst; $j$. formation of spores within eyst; $k$. separation of spores.

The Life-History of Amoebosporus saccharinum sp. nov.

The life-history of the second organism present is in many respects similar to the first, but it differs chiefly in the smaller size of the amoebae, cysts and spores. Moreover it does not appear to be of great economic importance since there is little evidence that it seriously affects the host. It is proposed to call this Amoebosporus saccharinum.

The earliest stage found consists of uninucleated amoebae which occur in some of the cortical cells as well as in the phloem and xylem parenchyma, but never in the xylem vessels. These amoebae are irregular in shape and are composed of very fine granular protoplasm quite distinct in character from that in A. vascularum. There is a central nucleus with a nucleolus lying in its centre. The nucleus divides by a process which appears to be mitosis, though insufficient stages were seen to determine this point with certainty. Concurrently with nuclear division the amoeba increases in size (Pl. LV figs. 10-12). Large plasmodia were not found though those containing up to six or seven nuclei occurred. The amoebae finally became surrounded with a cyst wall and the contents divided up into a number of small 
spherical cells each of which contained a single nucleus. (Pl. LV fig. 13). Pl. LV fig. 14 shews one in which the cyst has split and the contents migrated out into the surrounding cell. Fixation must have occurred during this process, since, while some of the spores remain within the cyst, others have already left it. As far as could be made out these bodies are provided with an apical flagellum, and at this early stage are pyriform in shape, though later they became rounded. There is a single nucleus which is situated either in the centre or towards the anterior end. The development of a flagellum does not take place until after the spores have left the eyst, and then not in every instance. In the majority the spores resemble those of $A$. vascularum in character but are smaller in size.

A third type of spore-like body was found in some of the cells which is represented in Pl. LV fig. 16. These bodies may be connected with one of the life-cycles described but it seems very improbable. They occur relatively rarely and may represent a stage in the life history of some other organism. The bodies are spherical, with a double wall of appreciable thickness, and contain a single dark staining body which appears to be a nucleus. No stage in their further development has been seen.

\section{Discussion}

It has been a matter of considerable difficulty to separate these two organisms, and 'only the culture of the two organisms separately on artificial media would prove conclusively that their life-histories are correct. Since I was working so far from the actual locality in which the disease occurred it was impossible for me to attempt to carry out such experiments, and I have had to rely exclusively upon a study of fixed material.

Assuming that I have made no mistake in the life-histories which I have indicated, it will be seen that neither organism bears any relationship with the Plasmodiophoraceae. With the exception of those stages represented in Pl. LV figs. 9-12 there is nothing which shews any similarity to any species of the Plasmodiophoraceae now recognised (2).

In the structure of the protoplasm and in the general appearance these two organisms undoubtedly belong to the Rhizopoda. Many Protozoa occur in plant tissue, though a critical study of them has not been made. In a recent paper (3) a short account has been given of one living in the roots of Apium nodiflorum, though in this instance the cysts have not been found to divide up into spores. These Protozoa occur in plants living in damp or badly drained soil. 
In Apium nodiflorum only plants growing by the side of a lake in a very marshy soil have been found to contain these amoebae. In the present instance it has been recorded that the disease is most common in low-lying badly drained soil (1). Such a position would be suitable for the development of saprophyte soil-inhabiting amoebae, which have become secondarily modified as parasites in plant tissue. I have been unable to determine the precise pathological effect which these organisms produce in the host, but, as Dr. Cook points out, the quantity of the organism is not sufficient to explain the effect by assuming that it merely causes a blocking of the larger xylem vessels. It has been repeatedly noticed that there is a marked tendency for the vessel to break during sectioning at a point where the parasite is developing which seems to indicate that an alteration has been produced in the material composing the cell wall, and that therefore the organism is not living merely as a saprophyte in the vessels. This is further confirmed by slight changes in the reactions to stains which is exhibited by these areas.

These organisms have been previously regarded as a single species under the name Plasmodiophora vascularum and Ligniera vascularum and although there are stages in the life-cycles which have not been completely investigated it seems desirable to give them scientific names since they are of definite economic importance to sugar canes in Puerto Rico. It is therefore proposed to place them in a new genus under the descriptive name Amoebosporus. The larger and more important will be called Amoebosporus vascularum, since it lives chiefly in the xylem vessels; and the smaller will be called Amoebosporus saccharinum. As regards their systematic position, the presence of amoebae and also cysts suggests relationship with the Rhizopoda and in particular with the family Lobosa in which pseudopodia are short, blunt, or absent. It is proposed, therefore, to place this new genus provisionally in that Family.

\section{SYSTEMATIC DIAGNOSIS}

The following Latin diagnoses of the new genus and the two species have been prepared.

Amoebosporus-gen. nov.

1 Amoebae quibus in cellulis hospitis cystes formatae sunt. Cystes in multis sporis dividiuntur. Sporarum amoebae formatae. In radicibus et caudicibus plantarum palustrium.

1. A. vascularum sp. nov.

Syn. Plasmodiophora vascularum Matz. pr. p.

Amoebae magnae. Cystes 16-22 $\mu$ diam. In cellulis lignis hos- 
pitis formatae sunt. Cystes in sporis dividiuntur. Sporae 2-3 $\mu$ diam. Sporae in amoebis pariuntur.

Hab. In radicibus et caudicibus Saccharum officinari in Porto Rico, West Indies.

2. A. saccharinum sp. nov.

Syn. Plasmodiophora vascularum Matz. pr. p.

Amoebae minutae. Cystes 10-12 $\mu$ diam. In cellulis phloemis et corticis hospitis formatae sunt. Cystes in sporis dividiuntur. Sporae 1.5-2 $\mu$ diam. Sporae in amoebis pariuntur.

Hab. In radicibus et caudicibus Saccharum officinari in Porto Rico, West Indies.

I wish to record my grateful thanks to Dr. Melville T. Cook for the very willing assistance which he has given me both by the loan of slides and also in collecting and fixing suitable material. I am also indebted to Dr. E. J. Butler, F.R.S. and Mr. S. F. Ashby of the Imperial Mycological Institute, Kew, for their assistance in examining and reporting upon some of the microscopic preparations.

February 1932.

REFERENCES

1. Cook, Melville T. Life-history of Ligniera vascularum (Matz) Cook. Journ. Dept. Agric. Porto Rico. 13:13-29. 1929.

2. Cook, W. R. Ivimey, The parasitic slime moulds. Hong Kong Naturalist. 3 No. 3. 1932.

3. Annales de Protistologie. 3: 197-200: 1932.

4. -_-_._- and Schwartz, E. J. The Life-History, eytology and method of infection of Plasmodiophora Brassicae Woron., the cause of Finger-and-Toe disease of cabbages and other Crucifers. Phil. Trans. Roy. Soc. London. 218 B: 283-314. 1930.

5. Matz, J. A new vascular organism of the Sugar Cane. Journ. Dept. Agric. Porto Rico. 4:41-46. 1920.

6. -.._-_La enfermedad de la Raíz de la Caña Azúcar. Estación Experimental Insular Porto Rico. Circ. 56 Pp. 12. 1921.

7. - Dry Top Rot of Sugar Cane. Journ. Dept. Agric. Porto Rico. 6:28-47. 1922.

\section{Description of Plates}

The drawings were made with a camera lucida at table level, with tube length $160 \mathrm{~mm}$. using a Zeiss $2 \mathrm{~mm}$. (N. A. 1.4) objective and compensating ocular $\times 15$ (Fig. 1-2, 8), compensating ocular $\times 7$ (Figs. 3, 9-15) and compensating ocular $\times 15$ (figs. 4-7, 16)

The photomicrographs were made a Zeiss $4.2 \mathrm{~mm}$. (N. A. 0.65) objective. The drawings and photographs have been reproduced 
without reduction, and actual magnifications are given after the description of each figure.

\section{PLATE LIII}

Fig. A.-A photomicrograph of $A$. vascularum shewing a mass of the cysts lying in a large xylem vessel. $\times 100$

Fig. B.-A photomicrograph of a small number of cysts of A. vascularum showing the division of the contents into separate spores. $\times 750$

Fig. C.-A photomicrograph of a transverse section through a vascular bundle showing the cysts in the central vessel surrounded by amoebae of $A$. vascularum. $\times 300$.

Fig. D.-A photomicrograph of a large xylem vessel showing the presence of a mature amoeba of $A$. vascularum lying within it. $\times 900$

\section{PLATE LIV}

Figs. 1-8.-Amoebosporus vascularum.

Fig. 1.-The spores after escape from the cyst showing the nucleus and associated vacuole. $\times 2475$

Fig. 2.-A later stage in the development of the spore after liberation into the vessel. The contents are becoming vacuolate, and the nucleus less distinct. $\times 2475$

Fig. 3.-A large amoeba lying in and completely filling a large vessel shewn in tranverse section. The amoeba at this stage does not shew any internal structure. $\times 1155$

Fig. 4.-A drawing of a large vascular strand shewing the presence of amoebae in several of the vessels. Three amoebae are present in the largest vessel one of which is shewing vacuolation. $\times 825$

Fig. 5.-A large amoeba in longitudinal section shewing the formation of cysts from within the amoeba. These cysts are now empty and some of the spore from them are seen lying in the upper part of the amoeba. $\times 825$

Fig. 6.-Four cysts shewing an early stage in the division into spores. The nuclei are visible. $\times 825$

\section{PLATE LV}

Fig. 7.-Part of a large amoeba containing both cysts and spores. The cysts are empty and their contents have passed out into the surrounding protoplasm which has not been involved in cyst formation. $\times 825$ 
Fig. 8.-A large mature cyst just before breaking. Shewing the contents divided up into a large number of spores each of which has a well-marked nucleus. $\times 2475$

Figs. 9-16.-Amoebosporus saccharinum.

Fig. 9.-A very young amoeba in which the protoplasm is just becoming differentiated. $\times 1155$

Fig. 10.-A slightly older amoeba developing within a small cell of the xylem parenchyma. $\times 1155$

Fig. 11.-An amoeba after the nucleus has begun to divide up. This amoeba was growing in the phloem tissue. $\times 1155$

Fig. 12.-An older amoeba with six nuclei developing in a cell of the phloem tissue. $\times 1155$

Fig. 13.-A late stage in the formation of cysts from the amoeba, shewing the contents dividing up prior to fragmentation. $\times 1155$

Fig. 14.-A cyst lying apparently quite free in a xylem vessel. The cyst has broken and some of the contents has escaped into the surrounding tissue. These spores appear to possess a single flagellum. $\times 1155$

Fig. 15.-Two young spores after escape and migration into the cortical tissue. The nucleus is clearly seen and the flagellum was visible. $\times 1155$

Fig. 16.-Spherical spores lying in a cell of the cortical parenchyma. It is doubtful if these represent a stage in either of the species described. $\times 825$ 